\title{
Isolation and identification of a pathogen, Providencia rettgeri, in Bombyx mori
}

\author{
Jiao Zhang ${ }^{1}$, Zhong-yuan Shen ${ }^{1,2,3 \star}$, Xu-dong Tang ${ }^{1,2}$, Li Xu ${ }^{1,2}$ and Feng Zhu ${ }^{1}$ \\ ${ }^{1}$ Jiangsu University of Science and Technology, Zhenjiang 212018, Jiangsu Province, China. \\ ${ }^{2}$ The Sericultural Research Institute, Chinese Academy of Agricultural Sciences, Zhenjiang 212018, \\ Jiangsu Province, China. \\ ${ }^{3}$ The Key Laboratory of Genetic Improvement of Silkworm and Mulberry of Agricultural Ministry, Zhenjiang 212018 , \\ Jiangsu Province, China. \\ Accepted 25 February, 2013
}

\begin{abstract}
A Gram-negative, rod-shaped bacterium, SY-1 strain, was isolated from a naturally infected silkworm Bombyx mori that was suffering from the common infection septicemia. The colony was round, slightly convex, smooth, moist, translucent, regular-edged and milky white on nutrient agar medium. The SY-1 was identified as a putative strain of Providencia rettgeri through its physiological and biochemical properties, and phylogenetic analyses performed using the 16S rRNA gene sequence. The SY-1 was identified as a putative strain of $P$. rettgeri. This is the first report demonstrating that $P$. rettgeri is pathogenic to $B$. mori. The identification of this strain adds to known kinds of pathogens that cause bacterial septicemia in the silkworm. This study aids the understanding of the prevention and control of the bacterial septicemia pathogens of $B$. mori.
\end{abstract}

Key words: Bombyx mori, bacterial septicemia, pathogen, Providencia.

\section{INTRODUCTION}

The silkworm, Bombyx mori, is an insect with high economic value which has been domesticated for silk production for more than 5000 years. It also occupied an important position in the human economic life and culture history. In China, sericulture is an important part of agriculture. However, bacterial diseases often cause severe economical loss in sericulture. Although, some kinds of bacterial diseases have been researched and described already, many bacteria which are pathogenic to the silkworm are unknown before now. So, the identification of new pathogenic bacteria for silkworm is very important.

Bacterial infection of silkworm, also known as flacherie, causes the silkworm cadavers to lose elasticity, become soft and rapidly rot. Silkworm bacterial flacherie are classified into three groups, namely, septicemia, bacterial

*Corresponding author. E-mail: szysri@yahoo.com.cn. Tel: 86511-85616665. Fax: 86-511-85616665 or 86-511-85628183. toxicosis and bacterial gastroenteric disease. Most bacterial septicemia pathogens of silkworm induce acute attacks. The time from pathogen infection to death may be more than $10 \mathrm{~h}$ at high temperature $\left(\sim 28^{\circ} \mathrm{C}\right)$, and approximately $24 \mathrm{~h}$ at low temperature (Jing, 2000). A diverse range of pathogenic bacteria can cause septicemia in the silkworm, including those belonging to the following genera: Bacillus, Enterobacter, Serratia, Aeromonas, Streptococcus, Pseudomonas and Staphylococcus. The virulence of these bacteria to the silkworm differ, and therefore, the symptoms of septicemia and course of disease are not uniform (Chen et al., 2008).

In our study, a previously unknown pathogenic bacterial strain SY-1 was isolated from a naturally infected silkworm. The cultured colony was translucent and milky white when grown on nutrient agar medium. The strain was identified as Providencia rettgeri according to its morphological, physiological and biochemical features, and by $16 \mathrm{~S}$ rRNA sequence analysis. In addition, the isolated strain was pathogenic to healthy silkworm when 
injected into the healthy fifth-instar larvae in the laboratory. P. rettgeri, which is widespread in nature and weakly virulent, is a member of the family Enterobacteriaceae, $P$. rettgeri has been reported to infect insects of Heterorhabditis spp. (Jackson et al., 1995).

It has also been reported that this bacteria can cause disease in animals, especially aquatic animals (Fan et al., 2001). Indeed, Fan and colleagues (2001) isolated $P$. rettgeri from caseous necrotic organs of a sick turtle. They then injected the bacteria into a healthy turtle, which induced disease and subsequent death. These results confirmed that this bacterium is pathogenic to turtle. Zhan Wen-bing et al. (1997) also isolated the bacteria from shrimp, and artificially infected shrimp in the laboratory, thereby demonstrating that this bacterium is pathogenic to marine aquaculture animals. John et al. (1979) also isolated this bacteria from polluted water and frog. In addition, $P$. rettgeri can cause human diseases, such as urinary tract infections and others external to the intestinal tract as well as many outbreaks in hospitals (Zhang, 2003). Yoh et al. (2005) demonstrated that Providencia spp., especially $P$. rettgeri, is a causative agent of traveler's diarrhoea, and that these species are important pathogens. Besides, P. rettgeri is also often found in bacteria as it is easy for food to get contaminated with this bacterium during processing, transportation and sales (Zhang, 2005). In addition, P. rettgeri has been reported to infect insects of Heterorhabditis spp.

The silkworm infected with the SY-1 exhibited symptom similar to those of bacterial septicemia. First, the infected silkworm stopped eating mulberry leaves and their movements slowed. Then, their bodies curled up, and they subsequently began vomiting and excreting soft waste. The corpses were stiff shortly after death. Furthermore, their bodies were soft and discolored, and the body wall easily ruptured, finally, foul-smelling liquid was released. To the best of our knowledge, this is the first report that $P$. rettgeri is pathogenic for the silkworm B. mori.

\section{MATERIALS AND METHODS}

\section{Test silkworm, strain and medium}

Experimental silkworm was provided by the pathology laboratory of the Sericultural Research Institute of Chinese Academy of Agricultural Sciences. Healthy newly molted fifth-instar larvae, whose variety are qiufeng $\times$ baiyu were used for the experiment. A naturally infected silkworm was collected in a farm in Sheyang City, Jiangsu Province. The corpse was disinfected with $70 \%(\mathrm{v} / \mathrm{v})$ ethanol for 1 to $2 \mathrm{~min}$ and washed twice with sterile distilled water after it had just began to soften. Then, we used sterilized insect needles to pierce the body wall and withdraw body fluid with an inoculation loop. The body fluid was then inoculated onto nutrient agar and cultured at $30^{\circ} \mathrm{C}$ for $48 \mathrm{~h}$ (Tao et al., 2011). Dominant single clones were purified by streaking and re-streaking the same agar plates. The purified strain, SY-1, was injected into prepared test silk-worms for the purpose of confirming the bacteria's pathogenicity. The clinical symptoms presented by the infected silkworm were observed and Koch's laws were used to investigate the pathogenicity of the strain (Liu et al., 1995).

Observation of colony characteristics and bacterial morphology

The strain was purified and incubated on a nutrient agar plate at $30^{\circ} \mathrm{C}$ for $24 \mathrm{~h}$. During this period, the colony characteristics, including size, color, transparency, humidity, shape and edge were observed.

The bacterial colony that had been cultured for $24 \mathrm{~h}$ was subjected to Gram's staining and observed using an oil immersion objective under a microscope. The cell morphology was examined under a JEM-1230 (Japan) scanning electron microscope at $40,000 \times$ magnification (Zhao et al., 2000).

\section{Phenotypic and biochemical characterization of SY-1}

Biochemical and physiological analyses were performed as described in Bergey's Manual (Holt et al., 1994) and the Manual for the Identification of Medical Bacteria (Barrow et al., 2004) together with relevant references of Brenner et al. (1978) and Penner et al. (1975).

\section{Preparation of genomic DNA of SY-1}

The phenol-chloroform method for extracting DNA was used as previously described (Xia et al., 2005).

\section{PCR amplification and analysis of the 16S rRNA sequence}

Universal primers for amplification of the bacterial 16S rRNA gene were used as previously reported (Weisburg et al., 1991). The forward primer was FT1 (5'-AGAGTTTGATCATGGCTCAG -3') and the reverse primer was RT5 (5'-ACGGTTACCTTGTTACGACTT-3'). The PCR reaction were performed as follows: $95^{\circ} \mathrm{C}$ for $5 \mathrm{~min} ; 30$ cycles of $95^{\circ} \mathrm{C}$ for $20 \mathrm{~s}, 50^{\circ} \mathrm{C}$ for $20 \mathrm{~s}$ and $72^{\circ} \mathrm{C}$ for $3 \mathrm{~min}$; and a final extension at $72^{\circ} \mathrm{C}$ for $10 \mathrm{~min}$. The PCR product was stored at $4^{\circ} \mathrm{C}$. Following the completion of the reaction, $5 \mu \mathrm{L}$ of the reaction solution and the stored PCR product $(45 \mu \mathrm{L})$ were subjected to $1 \%$ agarose gel electrophoresis. A DNA fragment $(\sim 1.5 \mathrm{~kb})$ was purified from the $1 \%$ agarose gel by using the commercial product for DNA purification PureLink quick extraction kit (Beijing Dingsheng Biotechnology Company). The PCR product was sequenced in the automated sequencing facilities at Shanghai Sangon Biotechnologies Co. Ltd. (China). The homology comparison of the almost complete 16S rRNA gene sequence of SY-1 was performed using the NCBI BLAST database (http://www. ncbi.nlm.nih.gov/). Subsequently, the sequence was analyzed on the Ribosomal Database Project (RDP) website (http://rdp.cme.msu.edu) (Cole et al., 2009) in order to obtain the 16S rRNA gene sequence (Holt et al., 1994). Sequence alignment was performed using ClustalX 1.83 software and the MEGA 4.0 software package. The phylogenetic tree was constructed using the neighbor-joining $(\mathrm{NJ})$ method and the genetic distances were calculated using the Kimura 2parameter method and 1,000 bootstrap replications to assess the stability of the relationships (Tamura et al., 2007).

\section{Pathogenicity to silkworm}

The cultured SY-1 bacteria was washed with 3.0 to $5.0 \mathrm{~mL}$ sterile 


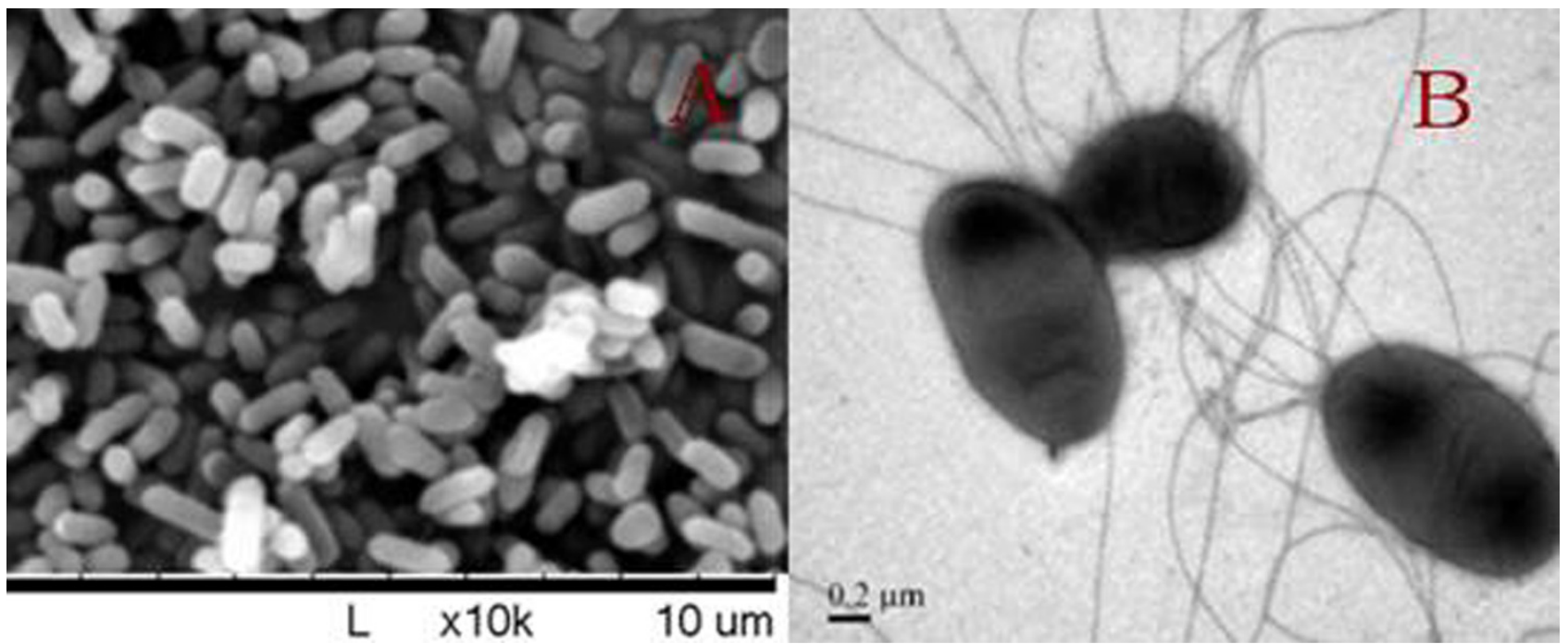

Figure 1. Morphological features of SY-1 using a scanning electron microscope. A: Stereoscan photograph, 10,000x. B: negatively stained electron microscope image, 40,000x.

phosphate-buffered saline (PBS) (2 mol/L; $\mathrm{pH} 7.4$ ) by repeated blowing and suction. Then, the bacterial suspension of SY-1 was transferred to a new sterile test tube and centrifuged at 4,000 rpm for $15 \mathrm{~min}$. The supernatant was removed and resuspended in $5 \mathrm{~mL}$ of PBS by oscillation to ensure the bacteria were uniformly distributed. The plate colony-counting method was used to count the number of bacteria (Luo, 2007).

The bacterial suspension of SY-1 was diluted into 7 solutions $(10$ $1,10^{-2}, 10^{-3}, 10^{-4}, 10^{-5}, 10^{-6}$ and $10^{-7}$ ) with sterile phosphate-buffered saline (PBS). Thirty healthy newly molted fifth-instar larvae in one experimental group were treated with the bacterial suspension by using a 10- $\mu \mathrm{L}$ microinjector and $2 \mu \mathrm{L}$ of bacterial suspension was injected into each larva. The same concentration of bacterial suspension was tested for three replicates under the same conditions. Concurrently, the control was set with $2 \mu \mathrm{L}$ of PBS only. Then, the infected larvae were reared at $25.0 \pm 1.0^{\circ} \mathrm{C}$. After $20 \mathrm{~h}$, the mortality of silkworm was recorded. Statistical analysis was completed using SPSS 16.0 (Jia, 2006), and the median lethal concentration (LC50) and regression equations were obtained.

\section{RESULTS}

\section{Description of colony and morphology of SY-1}

After routine culture on nutrient agar for $48 \mathrm{~h}$, the colony of the SY-1 strain was slightly convex, smooth, moist, translucent, regular-edged and milky white. The bacterial cell was Gram-negative, rod-shaped. Furthermore, electron microscopy results revealed that the cells were straight short rods measuring $1.3 \pm 0.2 \times 0.7 \pm 0.1 \mu \mathrm{m}$ with rounded ends and flagella (Figure 1).

\section{Physiological and biochemical characteristics of SY-1}

The results of the phenotypic and biochemical tests for SY-1 are presented in Table 1. The bacterium is found to be a facultative anaerobe which can utilize and produce acid by fermenting d-glucose, mannitol, rhamnose, dsorbitol, mannose, d-galactose, d-fructose and $10 \%$ lactose. It produced peroxidase and was tested to be positive for the deoxidization of nitrate. In addition, indole, urease, amylolysis, phenylalarine deaminase, utilization of malonate and methyl red tests were all positive. SY-1 was negative for produced acid from sucrose, maltose and I-arabinose. Voges-Proskauer reaction, gelatin liquefaction, tryptophan deaminase, ornithine decarboxylase, phenylalarine deaminase and arginine decarboxylase were also negative.

\section{S rRNA gene sequence and phylogenetic analysis}

The 16S rRNA sequence of SY-1 was 1504 bp (GenBank accession number: JQ954968), as expected. Alignment of the aforementioned sequence by using the RDP clearly demonstrated the taxonomic status of the SY-1 strain as follows: Bacteria (domain), Proteobacteria (phylum), Gammaproteobacteria (class), Enterobacteriales (order), Enterobacteriaceae (family), Providencia (genus). In the SeqMatch, 20 Providencia strains that had highly similar 16S rRNA gene sequences to SY-1 were retrieved from the RDP database. The S_ab scores obtained from the aforementioned alignment are shown in Table 2 . Furthermore, of the 20 strains, 8 were identified as $P$. rettgeri, and one each as Providencia stuartii, Providencia alcalifaciens and Providencia vermicola. Another 8 strains were identified in only the genus level (Providencia). The remaining sequence was an Enterobacteriaceae bacterium.

We also compared the 16S rRNA gene sequences by using NCBI BLAST http://www.ncbi.nlm.nih.gov/). 
Table 1. Physiological and biochemical characterization of the SY-1 strain.

\begin{tabular}{lclc}
\hline Characteristics & Response & Characteristics & Response \\
\hline Peroxidase & + & Argnine dihydrolase & - \\
Growth temperature $/ 4^{\circ} \mathrm{C}$ & + & Arginine decarboxylase & - \\
Growth temperature $/ 41^{\circ} \mathrm{C}$ & + & Utilization of malonate & + \\
Facultative anaerobic & + & Lipase (Tween 80 ) & - \\
Motility & + & Deoxidization of nitrate & + \\
Oxidase & - & d-Glucose (acid production) & + \\
ONPG production & - & d-Glucose (gas production) & - \\
Indole test & + & d-fructose & + \\
Trehalose & - & Sucrose & - \\
Gelatin liquefaction & - & rhamnose & + \\
Growth in 6.5\% NaCl & + & Maltose & - \\
Methylredtest & + & Lactose & - \\
VP reaction & - & 10\% lactose & + \\
Amylolysis & + & d-galactose & + \\
Urease test & + & d-mannitol & + \\
Utilization of sodium citrate & + & d-mannose & + \\
Tryptophan deaminase & - & d-sorbitol & + \\
Ornithine decarboxylase & - & d-cyclohexanhexol & + \\
Phenylalarine deaminase & + & L-arabinose & - \\
Lysine decarboxylase & - & Ethanol oxidation & + \\
\hline
\end{tabular}

Table 2. Similarity between the $16 \mathrm{~S}$ rRNA of the SY-1 strain and 20 other Providencia strains.

\begin{tabular}{llc}
\hline $\begin{array}{l}\text { Short ID } \\
\text { orientation }\end{array}$ & Strains & $\begin{array}{c}\text { S_ab score with the } \\
\text { 16S rRNA of SY-1 }\end{array}$ \\
\hline S000445102 & Providencia stuartii; PGS13; AY803746 & 0.977 \\
S000544654 & Providencia rettgeri (T); type strain: DSM 4542; AM040492 & 0.968 \\
S000550620 & Providencia sp. UTDM314; AY870456 & 0.984 \\
S000728634 & Providencia rettgeri; NCTC 11801; DQ885263 & 0.985 \\
S000769862 & Enterobacteriaceae bacterium ACU; EF151985 & 0.985 \\
S000968901 & Providencia sp. SBS1; EU195872 & 0.970 \\
S001044813 & Providencia rettgeri; CM7; EU660316 & 0.971 \\
S001044848 & Providencia rettgeri; CT23; EU660351 & 0.979 \\
S001095422 & Providencia sp. B282Ydz-ds; EU070350 & 0.969 \\
S001095844 & Providencia sp. YRL09; EU373416 & 0.980 \\
S001572543 & Providencia alcalifaciens; Acj 108; AB480755 & 0.963 \\
S001613563 & Providencia rettgeri; KR-3; GQ923882 & 0.969 \\
S001794733 & Providencia rettgeri; IITRP2; GU193984 & 0.972 \\
S002034338 & Providencia rettgeri; VITJCSTT3; GU457413 & 0.968 \\
S002167916 & Providencia vermicola; KSVDL-09-71600; HM071065 & 0.965 \\
S002228783 & Providencia sp. DGC-5; HM347050 & 0.985 \\
S002233507 & Providencia rettgeri; KPE62307H; HQ009881 & 0.989 \\
S002233997 & Providencia sp. R4-2A; HQ154555 & 0.970 \\
S002234011 & Providencia sp. R8-1A; HQ154569 & 0.967 \\
S002951763 & Providencia sp. BIHB 1402; JF766697 & 0.963 \\
\hline
\end{tabular}

Sequence similarities (>99\%) were identified between the $16 \mathrm{~S}$ rRNA gene of SY-1 and many Providencia strains.
Subsequently, 13 sequences that demonstrated high sequence homology with SY-1 or the other strains of 


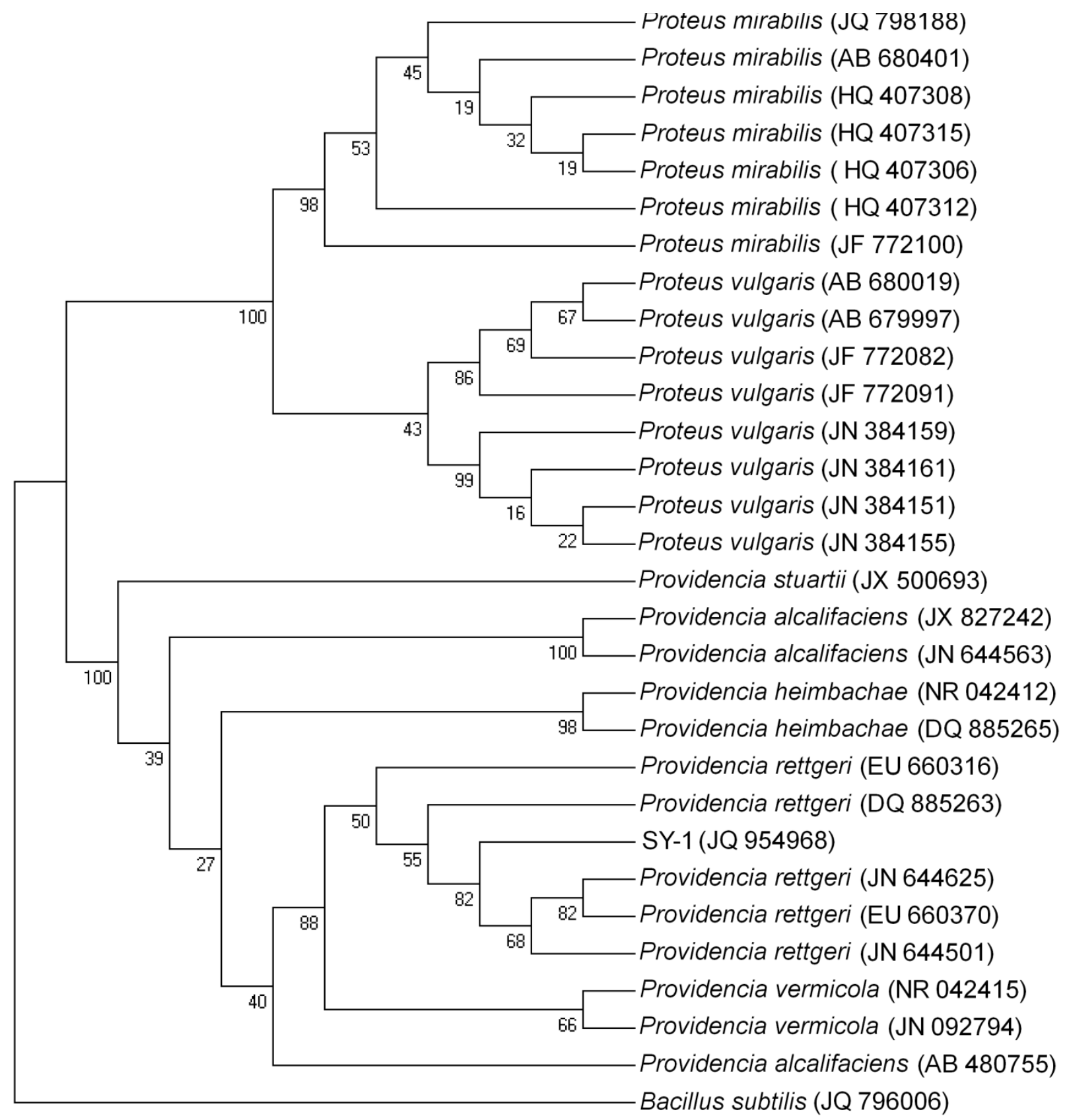

Figure 2. Phylogenetic tree of the $16 \mathrm{~S}$ rRNA sequences of the SY-1 strain. The phylogenetic tree was constructed by the NJ method. B. subtilis was used as the outgroup. The NJ consensus tree used 1,000 bootstrap replicates, and the number represents the percentage of bootstrap values.

species of Providencia besides $P$. rettgeri were selected. Previous DNA relatedness tests revealed that Providencia spp. are more closely related to Proteus vulgaris and Proteus mirabilis than to other members of the family Enterobacteriaceae (Holt et al., 1994). So, we selected 15 sequences of different $P$. vulgaris and $P$. mirabilis strains and compared them with the 16S rRNA gene sequence of SY-1. Furthermore, we used Bacillus subtilis (GenBank accession number: JQ796006), which is distantly related to members of the genus Providencia, as the outgroup. Thirty sequence alignments were performed using Clustal software and the MEGA 4.0 software package to generate the phylogenetic tree (Tamura et al., 2007) and assess the stability of the relationships (Figure 2).

The phylogenetic tree showed that several $P$. rettgeri strains had high sequence homology with SY-1. Therefore, according to its morphological characteristics 


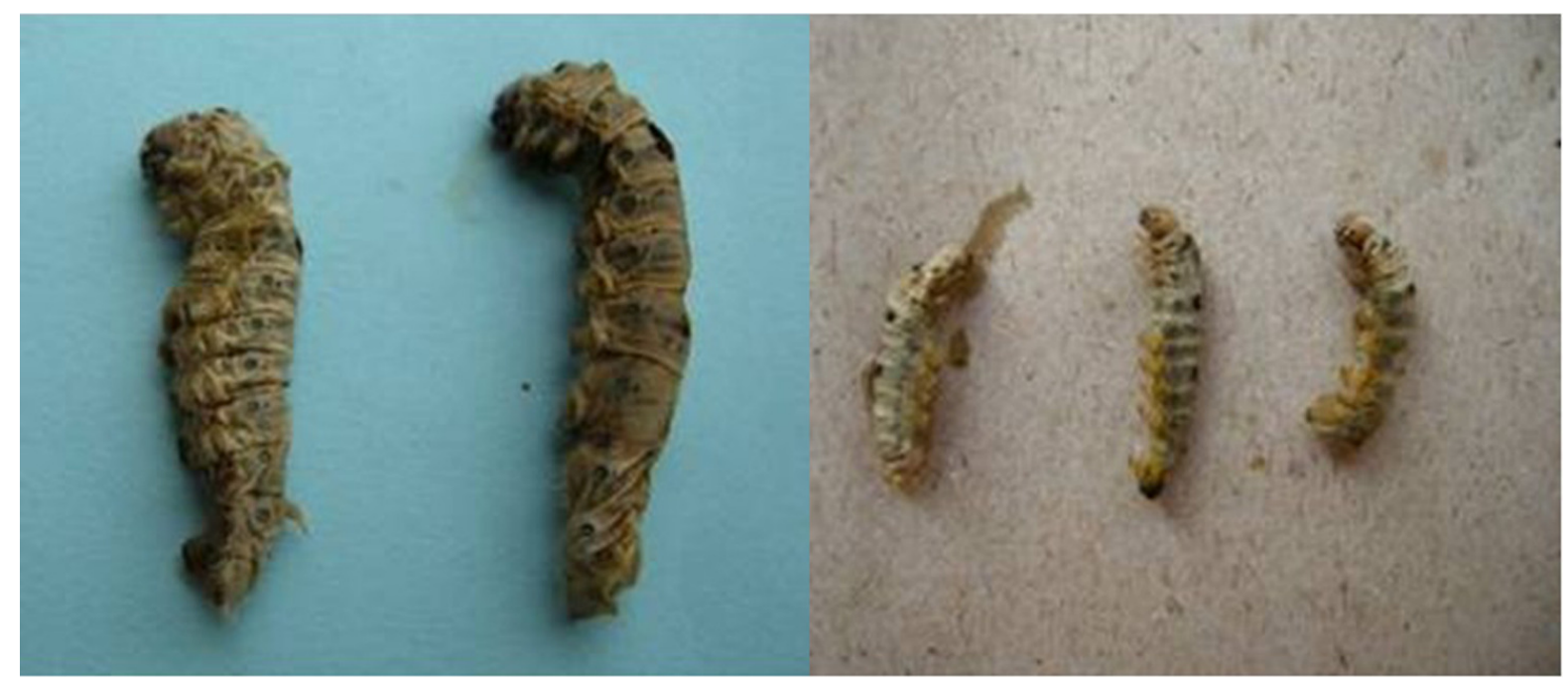

Figure 3. Dead silkworm infected by SY-1 bacteria.

Table 3. Pathogenicity of SY-1 strains against the silkworm.

\begin{tabular}{|c|c|c|c|c|c|c|}
\hline Strain & $\begin{array}{c}\text { Concentration } \\
\text { of bacterium } \\
\left(\times 10^{7} \mathrm{cfu} / \mathrm{mL}\right)\end{array}$ & $\begin{array}{c}\text { Corrected } \\
\text { mortality } \\
(\%)\end{array}$ & $\begin{array}{l}\text { Linear } \\
\text { regression } \\
\text { equation }\end{array}$ & $\mathrm{LC}_{50}$ & $\begin{array}{c}95 \% \\
\text { confidence } \\
\text { limits }\end{array}$ & $\begin{array}{l}\text { Pearson } \\
\text { correlation }\end{array}$ \\
\hline \multirow{4}{*}{ SY-1 } & 0.0084 & 20 & & \multirow{4}{*}{$1.4411 \times 10^{7}$} & \multirow{4}{*}{$\begin{array}{c}0.6561 \text { - } \\
2.9525\end{array}$} & \multirow{4}{*}{0.944} \\
\hline & 0.084 & 33.33 & $y=-$ & & & \\
\hline & 0.84 & 53.33 & $0.7870+0.2350 x$ & & & \\
\hline & 8.4 & 96.66 & & & & \\
\hline
\end{tabular}

and the physiological and biochemical properties, and the phylogenetic relation, the SY-1 was a strain of $P$. rettgeri.

\section{Pathogenicity to silkworm}

\section{Symptom in the infected silkworm}

The silkworms infected with SY-1 exhibited symptoms similar to those of bacterial septicemia. First, the sick silkworms stopped eating mulberry leaves and their movements became slow. Afterwards, some silkworm vomited, excreted soft waste and shrank, which resulted to the bodies of the diseased silkworm been much smaller than the normal larvae. Finally, the diseased silkworm went into convulsion and died. The corpses were stiff shortly after death, and the middle portion of each sector swelled due to tightening. The initial color of dead silkworm's body did not significantly differ from that of the normal silkworm. The body wall gradually contracted and some curled up, resulting in a C-shape. In addition, their color changed. Finally, the whole body was soft, flat and deflated, and the internal organs were broken down and liquefied, resulting in a foul-smell. Only the chitin in the skin remained, and the body gradually darkened and released a black liquid as it came across slight vibration (Figure 3).

\section{Pathogenicity test}

To test the ability of the SY-1 isolate to cause mortality of silkworm, different concentrations of the bacterial suspension were injected into healthy newly molted fifthinstar silkworm larvae. The peak mortality of the silkworm occurred between 23 and $26 \mathrm{~h}$ after inoculation. The control setting with $2 \mu \mathrm{L}$ of PBS only were all survived. And the corrected mortality for silkworm injected with $2 \mu \mathrm{L}$ of $8.4 \times 10^{4} \sim 8.4 \times 10^{7}$ colony forming units (CFU) $/ \mathrm{mL}$ bacterial suspension of SY-1was 20.0 to $96.66 \%$ at $26 \mathrm{~h}$ after injection. The linear regression relationship was $y=$ $-0.7870+0.2350 x$, and the medium lethal concentration was $L_{50}=1.4411 \times 10^{7} \mathrm{CFU} / \mathrm{mL}$ (Table 3).

\section{DISCUSSION}

In our study, on the basis of traditional morphology, the 
strain is Gram-negative and the cells of SY-1 bacteria were straight short rods measuring $1.3 \pm 0.2 \mu \mathrm{m} \times 0.7 \pm$ $0.1 \mu \mathrm{m}$ with rounded ends and flagella. The results of the physiological and biochemical characteristics showed it produced peroxidase and was tested to be positive for the deoxidization of nitrate. In addition, indole, urease, amylolysis, phenylalarine deaminase, utilization of malonate and methyl red tests were all positive. SY-1 tested negative for produced acid from sucrose, maltose and I-arabinose. Voges-Proskauer reaction, gelatin liquefaction, tryptophan deaminase, ornithine decarboxylase, phenylalarine deaminase and arginine decarboxylase were also negative. The bacterium is found to be a facultative anaerobe which can utilize and produce acid by fermenting d-glucose, mannitol, rhamnose, d-sorbitol, mannose, d-galactose, d-fructose and $10 \%$ lactose. Especially, the characteristic of producing acid by fermenting mannitol is different from other species of the genus Providencia and 16S rRNA gene sequence analysis. The phylogenetic tree showed that several $P$. rettgeri strains had high sequence homology with SY-1. It was finally identify as $P$. rettgeri. SY-1 has a higher pathogenicity to silkworm (B. morı). The linear regression relationship was $y=-0.7870+$ $0.2350 \mathrm{x}$, and the medium lethal concentration was $\mathrm{LC}_{50}=$ $1.4411 \times 10^{7} \mathrm{CFU} / \mathrm{mL}$. P. rettgeri belongs to pathogenic strain, which cannot only infect insects such as Heterorhabditis spp., having all kinds of symptoms, but also aquatic animals, such as turtle, shrimp, etc. Additonally, it can also lead to human diseases like urinary tract infections. Therefore, research on it has important public health implications.

To date, a wide variety of bacteria have been identified as pathogenic to silkworms, including Bacillus, Enterobacter, Serratia, Aeromonas, Streptococcus, Pseudomonas and Staphylococcus. However, in sericulture production, septicemia is mainly caused by the Bacillus spp., Serratia marcescens Bizio and Aeromonas spp. This is the first study to report that $P$. rettgeri is pathogenic to $B$. mori and that it causes typical septicemia symptoms. These results broaden our knowledge regarding the types of pathogens capable of inducing silkworm bacterial septicemia, as well as the requirements for the prevention and treatment of silkworm bacterial diseases. Furthermore, this study has enhanced our understanding of hosts for Providencia spp. These findings on silkworm disease in conjunction with the widespread of Providencia spp. in nature, and its influence on human and other animals, highlights the need for further research focused on the prevention and control of epidemic disease caused by this bacterium.

\section{ACKNOWLEDGEMENTS}

This work was supported by the earmarked fund for the China Agriculture Research System. We are grateful to all who provided the means for us to access free software, which we used and cited in this article. We thank all partners and laboratory members for their kind help and criticism.

\section{REFERENCES}

Barrow GI, Feltham RKA (2004). Cowan and Steel's manual for the identification of medical bacteria . UK:Cambridge University Press.

Brenner, DJ, Farmer JJ, Fanning GR, Steigerwalt AG, Klykken P, Wathen HG, Hickman FW, and Ewing WH( 1978). Deoxyribonucleic acid relatedness of Proteus and Providencia species. Int. J. Syst. Bacteriol. 28:269-282.

Chen YM, Huang JR (2008).Occurrence and control of the silkworm bacterial septicemia. Yun Nan Agricultural Science and Technology, z3.

Cole JR, Wang Q, Cardenas E, Fish J, Chai B, Farris RJ, Kulam-Syed Mohideen AS, McGarrell DM, Marsh T, Garrity GM, Tiedje JM (2009).The Ribosomal Database Project: improved alignments and new tools for rRNA analysis. J. Nucleic Acids Res. 37(Database issue), pp. 141-145.

Fan SH, Huang GQ, Guo AZ, Lu CP (2001).Organ abscesses of Chinese turtle caused by Providencia rettgeri. J. Nanjing Agric. University 24(4):71-74.

Holt JG, Krieg NR, Sneath PHA (1994). Bergey's manual of determinative bacteriology, 9th edn. Baltimore:Williams and Wilkins.

Jackson TJ, Wang HY, Miriam JN, Christine TG, Ann MB, Barbara CAD (1995). Isolation of insect pathogenic bacteria,Providencia rettgeri, from Heterorhabditis spp. J. Appl. Microbiol. 78(3):237-244.

Jia CS (2006). Calculating the LC50 of insecticides with software SPSS. Chin. Bull. Entomol. 43(3):414-417.

Jing W (2000). Silkworm Pathology . Beijing : China Agriculture Press. pp. $122-130$

John LP, Joan NH (1979). Application of O-Serotyping in a Study of Providencia rettgeri (Proteus rettgeri) Isolated from Human and Nonhuman Sources. J. Clin. Microbiol. 10(6):834-840.

Liu S, Zhu W, Yang ZR, Ge SR, He XY (1995). Isolation and identification of a pathogen of grasshoppers. Acta Microbiol. Sin. 35:86-89.

Luo TL, Shen LL, Bai YL, Xue Y (2007) Comparative study of Mycobacterium counting methods. J. Fourth Military Med. Univ. 28(4):353-357.

Penner JL, Hinton NA, Hennessy J(1975). Biotypes of Proteus rettgeri. J. Clin. Microbiol. 1:36-142.

Standardization Administration of the People's Republic of China.GB/T 4789.2-2008 Microbio-logical examination of food hygiene-Aerobic plate count. China Standard Press, Beijing.

Tamura K, Dudley J, Nei M, Kumar S (2007).MEGA4:Molecular evolutionary genetics analysis (MEGA) software version 4.0. Mol. Biol. Evol. 24(8):1596-1599.

Tao HP, Shen ZY,Zhu F, Xu XF,Tang XD, Xu L (2011). Isolation and Identification of a Pathogen of Silkworm Bombyx mori. Curr. Microbiol. 62(3):876-883.

Weisburg WG, Barns SM, Pelletier DA, Lane DJ (1991). 16S ribosomal DNA amplification for phylogenetic study. J. Bacteriol. 173(2):697703.

Xia H, Fu WL, Chen M, Huang Q, Zhao M, Zhao YH, Wang F, Luo Y (2005). Research about rapid extraction of bacterial DNA method. Mod. Prev. Med. 32:5.

Yoh M, Matsuyama K, Ohnishi M, Takagi K, Miyagi H, Mori K, Sam Park K, Ono K, Honda T (2005). Importance of Providencia species as a major cause of travellers' diarrhoea. J Med. Microbiol. 54(11):10771082.

Zhan WB, Zhou L, Chen ZQ,Yu KK, Meng QX (1997). A new shrimp pathogen-Providencia rettgeri. Fish. Sci. China 4(1):38-44.

Zhang GH (2005). The investigation of food poisoning caused by Providencia rettgeri. Shang Hai Prevention Medicine, 17:3.

Zhang ZR (2003). Clinical Microbiology and Microbiological testing.3rd ed. Beijing : People Hygiene Press, pp.136-140.

Zhao BG, Guo DS, Gao R (2000).Observation of the Site of Pine Wood Nematode where Bacteria are Carried with SEM and TEM. J. Nanjing For. Univ. 24(4):69-71. 